\title{
Social Informatics: 30 Years of Development of Russian Scientific School
}

\author{
Konstantin K. Kolin \\ Corresponding author: Konstantin K. Kolin [Константин Константинович Колин] (kolinkk@mail.ru)
}

Institute of Informatics Problems, Federal Research Center “Computer Science and Control”, Russian Academy of Sciences, Moscow, Russia

\begin{abstract}
The article deals with the history of the formation, current state and prospects for the development of social informatics as a current direction in science and education in Russia. The article offers mainly a personal view of the author, who has been involved in shaping social informatics in Russia for the last three decades. The article presents the distinctive features of the Russian scientific school of social informatics and its priorities in the formation of this field. The main directions of research in the field of social informatics in Russia in the context of the formation of the global information society are determined. Emphasis is placed on the interdisciplinary nature of many issues related to social informatics and their systematic study. Finally, the article summarizes the current necessity for the deep study of issues related to social informatics, e.g., information inequality, information crime, cyberbullies, manipulation of consciousness, virtualization of society, information wars, information poverty, information culture, and using computers to analyse social phenomena such as communication via social media. It is important not only in the area of scientific research but also in the system of secondary and higher education and training of scholars.
\end{abstract}

\section{Keywords}

Informatization; Information resources of society; Information society; Information security; Sustainable development.

\footnotetext{
Citation: Kolin, K. K. (2021). Social Informatics: 30 Years of Development of Russian Scientific School. Acta Informatica Pragensia, 10(3), 289-300. https://doi.org/10.18267/j.aip.150 


\section{Introduction}

Today, social informatics is one of the most important and promising areas in science and education not only in Russia and other post-Soviet countries. It studies the processes of information interaction in society in the context of its globalization and complex informatization. As a scientific field, social informatics has been developing in Russia for more than 30 years (Kolin, 2015). This is one of the most important sections of informatics - the science of information processes in nature and society. Currently, social informatics should be considered a scientific basis for the shaping of an information society. Social informatics studies new opportunities for and problems of a person in the conditions of an information environment for living and professional activity.

Kolin (2017) shows that an important trend in the development of civilization in the $21^{\text {st }}$ century is the transition from an industrial to a post-industrial society and then to an information society. This transition is already underway in many countries around the world. The main objects and results of work in the information society are information products and services. Therefore, there is an objective need for a systematic study of the problems of the shaping of the information society, the formation of scientific knowledge in this area and their dissemination through the education system. The natural reaction of science to this need was the formation of a separate area of research in the field of informatics, which appeared in Russia in the early 1990s and was called social informatics (Kolin, 1994).

The aim of the article is to present a brief summary and personal view regarding the focus and further development of social informatics in Russia from the perspective of its important representative Konstantin K. Kolin $\left({ }^{*} 1935\right)$, who has been involved in shaping this discipline in Russia for the last three decades. Therefore, this article refers mainly to the author's own publications. The profile of the author of this article and an overview of his other articles not only in the field of social informatics can be found in the official Russian registers: (ISTINA, 2021; RIC, 2021). This article was prepared at the request of the editors of the journal Acta Informatica Pragensia for a special issue Perspectives of Social Informatics. The reason for its writing is to introduce the Russian school of social informatics and its basic thoughts, development, and possible future directions to non-Russian speaking scholars.

\section{Social Informatics as a Scientific Basis for the Shaping of the Information Society}

The first work in which social informatics was presented as an independent scientific direction, which examines principles of informatization of society, was the monograph "Informatization of Society: Introduction to Social Informatics" (Ursul, 1990a) of the famous Russian philosopher academician Arkady D. Ursul (1936-2020); see Figure 1. Prior to this publication, the term "social informatics" was also used in the Soviet Union from the 1970s, but mainly in the area focused on study of problems of scientific information (Sokolov, 1988). Ursul's concept of social informatics already builds on a new concept of informatics as a broad computer and information-oriented discipline according to the broad European tradition (Glushkov, 1987). Until the 1980s, the concept of informatics was associated mainly with the theory of scientific information.

Therefore, Ursul is the founder of the modern scientific school of social informatics in Russia (Kolin, 2016). His philosophical approach to social informatics connected informatics with the global problem of informatization of society, in the process of which the "socialization" of theoretical achievements and practical applications of informatics is carried out. Ursul showed that the process of informatization of society should be humanistically oriented in its very essence. At the same time, the means of informatics and new information technologies should act only as tools that serve humans so that they can more effectively master information and use it for social progress. 


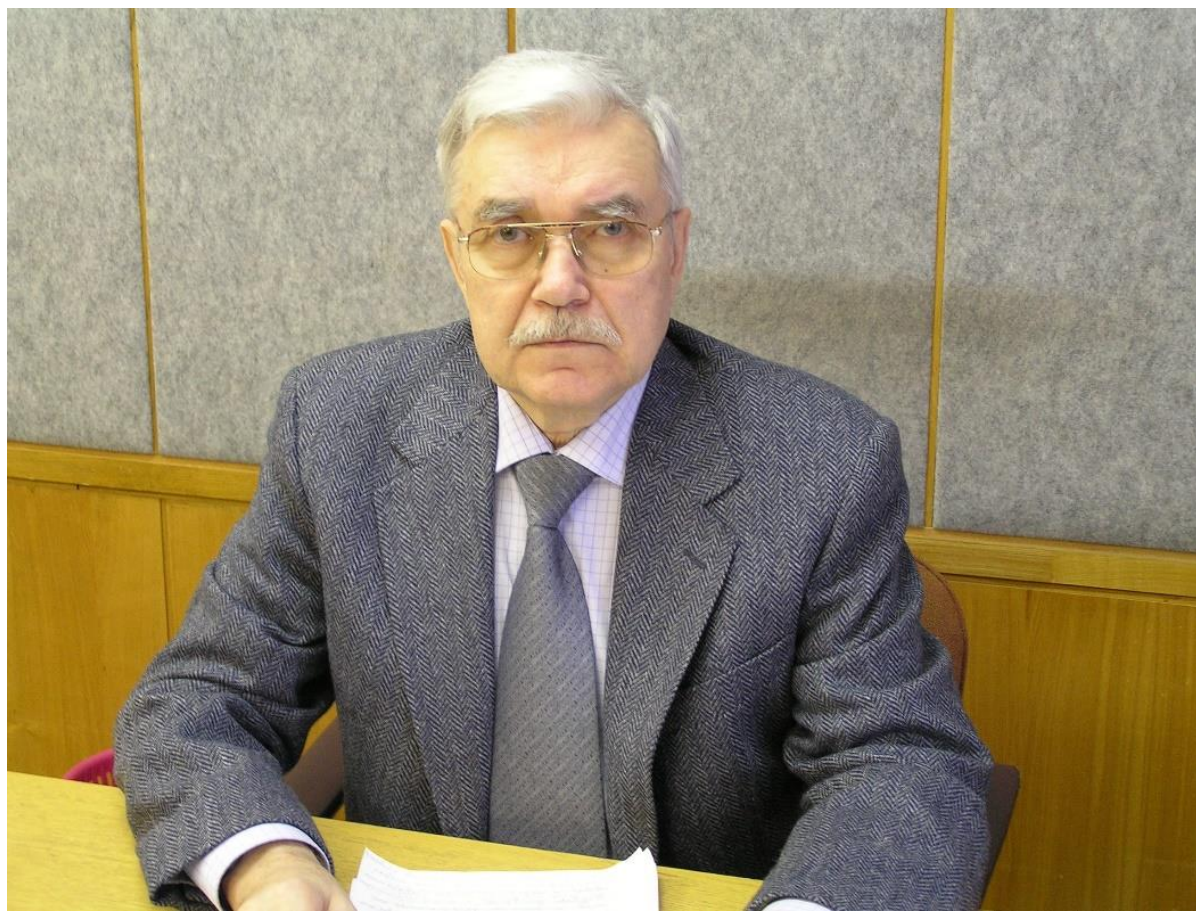

Figure 1. Arkady D. Ursul. Source: (Kolin, 2016).

Ursul's philosophical works note the fundamental importance of the humanistic orientation of the informatization process of society, which should not develop spontaneously, because it creates not only new opportunities for man and society, but also new threats (Ursul, 1990b). This is what determines the relevance of conducting a complex of scientific studies aimed at studying the regularities of the process of informatization of society. The results of these studies should be scientifically based concepts, forecasts and recommendations in the field of international and national scientific, technical, economic, social, educational and cultural policies in the area of informatization of society. The development of social informatics as a science and educational discipline should contribute to the solution of these problems. It should become the scientific basis of the global information society that is already being formed today (Castels, 2000), which many scientists consider to be a new, higher stage of the development of civilization (Kolin, 2002).

\section{Object and Subject of Social Informatics Research}

Social informatics was formed at the junction of a number of natural and social sciences and humanities under the influence of integrative factors caused by the need to form the scientific base of the postindustrial civilization - the information society. In the works of specialists of the Institute of Problems of Informatics of the Russian Academy of Sciences, which were published in the early 1990s, the legitimacy of the establishment of social informatics as an independent scientific discipline is sufficiently justified; see Kolin (1990). Basic criteria for establishing social informatics as a discipline are the presence of its own object and subject of research, as well as the methodology of their implementation characteristic of this discipline.

The object of social informatics research is the manifestations of information reality in the society. In other words, social informatics studies the sum of all types of information resources, processes, technologies, systems and communications that are of social significance for the life support and development of society (Kolin, 1993).

The subject of social informatics research is the properties and regularities of information resources, processes, technologies, systems and communications in the social sphere. At the same time, a comprehensive study of the process of informatization of society, its impact on social structures, as well 
as on the role and position of the individual in society is particularly important (Kolin, 1995a). The analysis has shown that this effect is two-sided, i.e., it is a two-way effect. The social structures of society and people's attitude to the process of informatization, in turn, have a significant impact on the nature and pace of development of this process (Kolin, 1995b).

According to Ursul, one of the fundamental problems of social informatics is the problem of the coordinated development of society and the process of its global informatization. This problem is currently particularly important, as it is most closely related to the problem of overcoming the systemic crisis of civilization and its transition to the path of sustainable and safe development based on the mastery of information, as well as the widespread use of new knowledge and information technologies. Therefore, the priority tasks of research in this area should be considered to identify and analyse the capabilities of people and society to effectively use information resources and information technologies, taking into account the new threats that already exist today in connection with the global informatization of society or may appear in future.

\section{Methodological Basis of Social Informatics}

The problems of forming a new human environment in the context of the shaping of the information society are so significant that they should be systematically studied by various scientific disciplines. Among them, it is necessary first of all to highlight cultural studies, sociology, economics and political science, as well as psychology and pedagogy. The fundamental difference in the approach to the study of these problems in the framework of social informatics is that the main scientific presumption of informatics is used. Its essence is that the world around us has the property of informational unity. Therefore, the regularities of the manifestation of information as a universal property of matter in nature and society should have a common primary basis (Kolin, 2006b).

The scientific basis for the development of social informatics is the achievements in the field of philosophy of information and theoretical foundations of informatics (Kolin, 2010b; Kolin, 2012). As for its own scientific methodology, social informatics is still in the process of formation. An important distinguishing feature of this methodology is the use of a combination of different methods of scientific approach to the problems of analysis and synthesis of the studied problems and processes. The main ones are systems, information and coevolutionary approaches, as well as scientific approaches used in the social branches of modern science. These three approaches are briefly introduced:

The systems approach allows a holistic view of any system. The basic principle is the purposeful definition of the system (elements and their relationships) and thus the boundaries of the system and also the researched problem. The systems approach has a long tradition in Russia. The following two approaches also build on systems thinking.

The information approach. The essence of the information approach is that when studying a certain process or phenomenon, its information aspects are first highlighted (Kolin, 1998). Experience has shown that this allows us to see many seemingly familiar processes and phenomena in a completely new light, to reveal their informational essence, which in many cases is the main reason for a particular direction of development of these processes.

The coevolutionary approach to the problems of social informatics is the need to take into account the inseparable unity and mutual influence of the processes of development of society and its informatization: their coevolution (Ursul, 1990b). This approach is reflected in the Okinawa Charter for the Global Information Society (MOFA, 2000), which some scholars call the "international constitution" of the information society.

The methodological apparatus of social informatics, in addition to the above approaches, includes methods of information modelling of the studied processes, as well as traditional methods of monitoring 
and forecasting. It should be expected that the composition and power of the methodological apparatus of social informatics will actively develop with the expansion and deepening of its subject area and the need to solve new problems put forward by the practice of the development of the information society.

\section{Structure of Subject Area of Social Informatics}

The structure of the subject area of social informatics was defined in Russia in the early 1990s (Kolin, 1993) and remains relevant to the present day. It was discussed at a number of scientific forums. The most significant of them was the Second International Congress of UNESCO "Education and Informatics" in Moscow (UNESCO, 1996). In Russia's national report at the congress, the section Social Informatics was singled out as one of the four main sections of the new course named Fundamental Foundations of Informatics, which was recommended in the final documents of the congress for a promising education system (Kolin, 1996).

In the modern structure of the subject area of social informatics, Russian scientists distinguish the following main areas of research:

- Study of the general laws of the process of informatization of society.

- Research of information resources of the society (their types, properties, structure and topology). The study of the needs of society in information resources to achieve the goals of social development.

- Research of the information potential of the society, which determines its capabilities for the formation and effective use of information as a strategic resource for development. This includes problems related to the creation of the information infrastructure and the information environment of the society, the creation and operation of centres for the generation, storage and distribution of information resources, as well as the development of tools and technologies that ensure the activation and effective use of information resources.

- Research of the problems of the formation of the global information society, the patterns and features of its formation and development prospects. This includes the problems of the information economy, changes in the structure of employment of the population, as well as the problem of information democracy, in which the availability of information and its reliability are particularly important, as the most important conditions for the practical realization of people's civil rights and freedoms. The development of the intellectual potential of the society is essential for solving these problems. The ability to produce and assimilate new knowledge, as well as the development of an information culture that characterizes the ability of society to adapt to the new information environment of human habitation are also relevant topics.

- Comprehensive study of human problems in the information society. It should study new opportunities and problems of personal development in the information society, a person's education and upbringing, the development of his creative abilities based on the achievements of computing and creative information technologies. The problems of a person's information freedom and information security and overcoming technological and linguistic barriers that arise in the new information space are also relevant.

Practice has shown that the above structure of the problem area of social informatics was quite successful, and the listed problems that make up this area still continue to be important and relevant. This is evidenced, in particular, by the large number of references to the publications of Russian scientists mainly in Russian but also in international databases of scientific publications. For example, the number of 
references to the monograph Kolin (2000) written by the author of this article on social informatics in the database E-library.ru has exceeded 385 and continues to grow.

\section{Educational Aspects of Social Informatics in Russia}

The following subsections present the main educational aspects that are reflected in the understanding of social informatics in Russia and other post-Soviet countries.

\subsection{Social informatics, education and scientific worldview}

Comprehensive study of the processes of informatization of society and the emerging new information reality is extremely important not only from a pragmatic point of view, but also in the humanitarian aspect. It contributes to the formation of a modern scientific worldview. The usual stereotypes of people's behaviour, as well as their traditional ideas about space and time, wealth and poverty, equality and inequality, freedom and responsibility, and quality of life are changing significantly in the context of the emergence of the information society (Kolin, 2010a).

Research shows that the quality of life in modern society is largely determined by the availability of the necessary information and information communications, as well as the level of consumption of information products and services (Kolin, 2007). Therefore, such concepts as information inequality, information poverty, individual information culture, e-government and many others have appeared and are increasingly being used.

The information sector of the economy is developing rapidly. In a number of countries, such as India, it has already become one of the most important sources of product exports and job creation. In many countries, including Russia, open education systems based on the use of digital educational resources and distance learning technologies are increasingly developing. An additional incentive here was the coronavirus pandemic (COVID-19), which today has affected almost all countries of the world and forced them to more widely use distance learning methods in the field of general and higher education, advanced training of certified specialists and training of scientific personnel.

The formation of smart education is intensively developing in the Western countries. It involves the transfer of the educational process mainly to an electronic environment that provides effective learning using digital content that is freely available. This approach makes learning accessible everywhere and always, brings together educational institutions and teaching staff to implement joint educational activities on the Internet. It should be noted that the Internet today is one of the main sources of knowledge for students. This is the so-called "flexible learning" based on common technologies, standards and agreements.

\subsection{Information security}

Information security is currently one of the most important conditions for ensuring national and international security, as well as everyone's personal security (Sokolov \& Kolin, 2009). It is a complex problem that has both technological and social aspects (Kolin, 2006a). The global financial and economic crisis that has engulfed many countries is a very clear example here.

At the present stage of the formation of a knowledge-based society, the strategic importance of the development of the information culture that influences individual and society is clear (Kolin, 2011b). The problem of multilingualism in the information society (e.g., online communication) can be mentioned. After all, language is not only a means of communication, but also a means of cognition, it is a "space of thought" necessary for information modelling of the surrounding world in the human mind (Kolin, 2005a). 


\subsection{Relevance of information orientation of Russian education system}

Social informatics has been developing actively in Russia for more than 30 years. Currently, it is one of the most important sections of informatics in Russia, which is the scientific basis for the formation of the information society, as well as for the study of a person's new opportunities and new problems in the conditions of the formation of a fundamentally new information environment of his life and professional activity.

Many problems of social informatics are studied at secondary and higher schools of Russia, as well as in the system of training for scientific personnel and advanced training of certified specialists. However, the education system today faces a new urgent problem - to prepare millions of citizens, and especially the new generation, for life and professional activity in the global information society in a timely manner. The analysis shows that to solve this problem, it is necessary to significantly increase the information orientation of the content of the education system (Sokolov \& Kolin, 2009).

A constructive solution here can be the widespread introduction of the general education discipline "Social Informatics" into the education system, which aims to ensure the formation of new knowledge and skills that people need in the new information environment.

\subsection{Experience of Teaching of Social Informatics in Russia}

Russia is a world leader in the field of studying the problems of social informatics in the education system. This process began in Russia in the late 1980s, when the social significance of the process of informatization of society began to be realized. During this period of more than 30 years, specialized departments of social informatics were established at a number of Russian universities. For example, in 1990, the Institute of Social Informatics was established at the Academy of Social Sciences under the Central Committee of the Communist Party of the Soviet Union. Arkady D. Ursul was its director. The Russian Association of Departments of Social Informatics was also established, which continues its work to the present day. Boris A. Suslakov was elected $\left({ }^{*} 1943\right)$ its head.

In the mid-1990s, the world's first Faculty of Social Informatics was established at the Moscow State Social University (its new name is the Russian State Social University) on the initiative of the Institute of Problems of Informatics of the Russian Academy of Sciences. It functioned successfully for five years and trained a significant number of specialists with the qualification of Sociologist-Informatic Expert (from the US perspective sociology-computer science-information systems). The author of this article developed and taught at this faculty an innovative course "Philosophy and History of Education", which showed the importance of studying the information aspects of the development of civilization.

The experience of the educational activities of this faculty was reported by Russian scientists at the $2^{\text {nd }}$ International Congress of UNESCO "Education and Informatics" and approved by the participants of that Congress (Kolin et al., 1997). Its recommendations are still successfully used in a number of higher education institutions in Russia.

The first social informatics programme for the higher education system, which took into account the recommendations of the UNESCO Congress, was developed in 1997 at the Institute of Problems of Informatics of the Russian Academy of Sciences. Its implementation in the education system was carried out with the active assistance of the UNESCO Institute for Information Technologies in Education. In the following years, the programme was developed to the level of a full-fledged Basic Modular Programme, which is available via the Internet and is well known to specialists working in the field of education (Kolin, 2001).

In accordance with the content of this programme, a textbook for the higher education system titled "Social Informatics" was developed in Russia (Kolin, 2000; Kolin, 2003). Based on the Russian-Chinese scientific cooperation, this publication was also translated into Chinese in 2010. 


\section{Perspectives for Development of Social Informatics}

The research of Russian scientists has shown that the promising directions of the development of social informatics are not limited only to the study of the problems of informatization and the shaping of the information society. After all, many socially significant manifestations of the phenomenon of information are not necessarily related to the processes of informatization of society, and social informatics should also study these manifestations of information reality. Therefore, the most promising areas of further development of social informatics include the following:

- Systematic studies of the problems of the formation of a global information society based on knowledge, and related problems of science, technology, economy, education and culture.

- Comprehensive study of the problems of formation of electronic information resources, methods of their preservation and effective use in various spheres of society.

- Study of new opportunities for human development in the information society, including their intelligence, creativity and moral qualities. This involves the development of cognitive technologies, as well as computer graphics, which activates the right hemisphere of the human brain and its spatial imagination.

- Research of social problems of information security, including such problems as information inequality, information crime, cyberbullies, manipulation of consciousness, virtualization of society, as well as confrontation in the information sphere and information wars.

Some of these problems are already being studied by other scientific areas. However, it is necessary to stimulate them not only at the national level, but also at the international level. The fact is that the information environment of human habitation is developing so rapidly today that we can expect radical changes in all spheres of society's life in the coming years (Kolin, 2018). The reasons for this will be new opportunities for global information communications, as well as the rapid development of artificial intelligence tools and methods. Blockchain technologies in the economy, medical and industrial robots, unmanned vehicles, virtual and augmented reality technologies - all these innovations are already entering our lives today. In the coming years, they will become familiar attributes of the culture of society in the middle of the $21^{\text {st }}$ century.

According to the available Russian forecasts, the living and working conditions of people in developed countries in two decades will be as different from current conditions as our times are different from the era of Renaissance. Moreover, these changes will occur not only in the scientific, technical, economic and information fields, but also in the fields of culture and art, in the conditions of people's everyday life and recreation. A new, actively developing society information culture will come into existence. There will be new types of arts, new medicine and new types of communication among people, which will be based on information and telecommunications systems, information services and user-friendly interfaces.

In other words, a new habitat, which is increasingly called information cyberspace, is already being formed and will be increasingly widespread on our planet. The impact of cyberspace on humans and how people adapt in this space create new challenges for basic science and the education system. All these problems should become the subject of study of social informatics in the coming years.

As for the changes in the social aspects of the development of society, we should expect not only positive results, but also new global problems. One of them is the problem of increasing information inequality of people, countries and regions in the new information environment. To reduce the social severity of this problem should be the role of the education system, the information orientation of which should be significantly strengthened. At the same time, the informatization of education should be transferred from the instrumental and technological level to the content one. Its main goal should be the shaping of people's 
information worldview and a new information culture (Kolin \& Ursul, 2011). At the same time, an important part of this culture should be the culture of information security (Kolin, 2006a).

Therefore, a comprehensive study of the problems of social informatics, not only in academic science, but also in the education system, is an extremely relevant and socially significant problem today. Its solution requires the joint efforts of the world scientific and educational community and, of course, the corresponding modernization of the education system and the training of scientific and pedagogical personnel.

\subsection{Social informatics as a field of data-intensive science}

Social informatics studies information processes in society, which are becoming more and more intensive under the influence of informatization. It is enough to indicate that the number of Internet users already exceeds 3 billion. According to the UN, the global level of Internet technology penetration exceeded 50\% in 2018 (UN, 2018). The dynamics of this process is such that we can talk about the advent of the era of the global information society, which was previously predicted only in the middle of the $21^{\text {st }}$ century.

Unfortunately, today this global socio-technological phenomenon is not yet sufficiently understood and does not find necessary reflection in research programmes and in the education system. At the same time, the analysis shows that the global information society opens up fundamentally new opportunities for scientific analysis and forecasting of many social processes, i.e., for studying the dynamics of society itself using the methodology of social informatics. It is enough to point out the possibility of using data on information communications in social networks for this purpose, which represent a new area of activity of millions of people.

Analysis of information flows on the Internet today allows us to produce large-scale sociological research without resorting to traditional methods of sociological surveys. Moreover, as the number of users of this network continues to increase, the research results will become more and more reliable. In addition, over the past decades, massive collections of data on various areas of society's life activity have been formed.

A typical example here is the collection of data on various aspects of cultural activities obtained as a result of the implementation of the European project "Observatory of Culture". They contain information about the topics of various cultural events: film festivals, theatre productions, pop concerts, etc. The analysis of this information is necessary in order to get an idea of the main trends in the development of modern culture, which, according to many experts, is in a state of systemic crisis (Kolin, 2014).

However, to do this, it is necessary to ensure the appropriate orientation of social informatics, as well as to prepare the necessary personnel to work with intensive information flows and massive data collections. This is exactly the case when quantity turns into quality, i.e., we are dealing with a fundamentally new problem of intensive use of large-volume data, which is called Big Data.

\subsection{Interdisciplinary nature of social informatics problems}

To solve the problems of large-volume data analysis listed above, it is necessary to conduct interdisciplinary research and development. At the same time, it is necessary to ensure the advanced development of informatics tools and methods for semantic search and analysis of texts in multilingual collections of social and cultural information data. This task is becoming a priority for the development of social informatics in the coming decades (Kolin \& Khoroshilov, 2012).

At the same time, it is necessary to point out that the research of society and its culture using the means and methods of informatics is the task of other scientific disciplines that are already being formed at the present time and which can be called, respectively, information sociology and information culturology (Kolin \& Ursul, 2015). 


\section{Conclusion}

The conducted research has shown that global informatization is one of the dominant trends in the socioeconomic, scientific, technical and cultural development of society in the $21^{\text {st }}$ century, and the level of information development of the country largely determines the quality of life of the population, the development of science, education and culture, the country's maturity or national security.

An analysis of the current geopolitical situation and trends in its further development shows (Kolin, 2020a) that in the coming years, cybersecurity, as well as the social aspects of information security, due to the purposeful deformation of public consciousness with the use of mass media and social networks on the Internet, will become priorities for ensuring national and global security (Kolin, 2005b). These threats are reflected in the new Russian Military Doctrine, in the US Cybersecurity Strategy, and are included in the text of the new Information Security Doctrine of the Russian Federation, which was adopted in 2016.

To effectively counter these threats, it is necessary to actively develop a new direction of society's culture - the culture of information security (Kolin, 2020b). This task was set by the Russian Security Council at the end of 2013. Therefore, it is important that this strategically important task is reflected in the information security strategy of Russia, which is currently being developed in accordance with the instructions of the President of Russia, as well as in international projects for the development of social informatics.

For problems of this magnitude, it is not enough to develop problem-solving procedures. It is also necessary that the importance of this problem is recognized in society. Only then will it be possible to create an international cooperation of specialists of various profiles, members of the government, representatives of business and civil society, which is necessary to solve this problem, the importance of which is rapidly growing.

To this end, it is necessary to intensify comprehensive study of the processes of development of the global informatization of society in science and education. At the same time, the 30 years of experience of Russia in the field of studying the problems relevant for social informatics can be extremely useful.

\section{Additional Information and Declarations}

Conflict of Interests: The author declares no conflict of interest.

Author Contributions: The author confirms being the sole contributor of this work.

Information about the author: Konstantin K. Kolin - Doctor of Technical Sciences, Professor, Honoured Scientist of the Russian Federation. Principal researcher of the Institute of Informatics Problems of the Russian Academy of Sciences. President and Research supervisor of the Analytical Centre for Strategic Studies "SOKOL". Academician of Russian Academy of Natural Sciences and International Global Research Academy.

\section{References}

Castels, M. (2000). The Information Age: Economy, Society and Culture. Blackwell.

Glushkov, V. M. (1987). Fundamentals of Paperless Informatics. Nauka. https://bookree.org/reader?file=792216\&pg=3

ISTINA. (2021). Колин Константин Константинович. Intelligent System for Thematic Research of Scientometric Data, Lomonosov Moscow State University. https://istina.msu.ru/profile/kolin35/

Kolin, K. K. (1993). Actual problems of social Informatics. In Social Informatics-93 (pp. 5-18). Institute of Informatics Problems of the Russian Academy of Sciences. https://www.elibrary.ru/item.asp?id=26077505

Kolin, K. K. (1994). Social Informatics - the scientific basis of post-industrial society. In Social Informatics-94 (pp. 4-23). Institute of Informatics Problems of the Russian Academy of Sciences. https://www.elibrary.ru/item.asp?id=25788353

Kolin, K. K. (1995a). Social Informatics a new direction of scientific research on the complex problem of "Informatics". Systems and means of Informatics, 7, 20-37. https://www.elibrary.ru/item.asp?id=26794604 
Kolin, K. K. (1995b). Science for the Future: Social Informatics. Information resources of Russia, 3, 8-15. https://www.elibrary.ru/item.asp?id=26633585

Kolin, K. K. (1996). Informatics in the System of Advanced Education. Academy of Natural Sciences of the Russian Federation. https://www.elibrary.ru/item.asp?id=26173626

Kolin, K. K. (1998). The Information Approach as a fundamental method of cognition. Intersectoral Information Service, (1), 317. https://www.elibrary.ru/item.asp?id=25706267

Kolin, K. K. (2000). Fundamentals of Informatics: Social Informatics. A textbook for universities. Academic Project. https://www.elibrary.ru/item.asp?id=25753714

Kolin, K. K. (2001). Social Informatics. Basic modular program of the training course for the higher education system. IPI RAS. https://www.elibrary.ru/item.asp?id=25795614

Kolin, K. K. (2002). Information Civilization. IPI RAS. https://www.elibrary.ru/item.asp?id=25731749

Kolin, K. K. (2003). Social Informatics: A textbook for universities. Academic Project. https://www.elibrary.ru/item.asp?id=25731567

Kolin, K. K. (2005a). Innovative development in the Information Society and the Quality of Education. Open Education, (3), 6372.

Kolin, K. K. (2005b). Neoglobalism and Culture: New Threats to National Security. Knowledge, Understanding, Skill, (2), 104111. https://www.elibrary.ru/item.asp?id=11136265

Kolin K. K. (2006a). Information Security as a humanitarian problem. Open Education, (1), 86-93. https://www.elibrary.ru/item.asp?id=11718417

Kolin, K. K. (2006b). The formation of Informatics as a fundamental science and a complex scientific problem. Systems and means of Informatics, 16(3), 7-57. https://www.elibrary.ru/item.asp?id=13060515

Kolin, K. K. (2007). Man in the Information Society: New Challenges for Education, Science, and Culture. Open Education, (5), 40-46. https://www.elibrary.ru/item.asp?id=12939269

Kolin, K. K. (2010a). Quality of Life in the Information Society. Man and Labor, (1), 39-43. https://www.elibrary.ru/item.asp?id=26331926

Kolin, K. K. (2010b). Philosophical Problems of Informatics. BINOM, Laboratory of Knowledge. https://www.elibrary.ru/item.asp?id=20117014

Kolin, K. K. (2011). Information space of culture: The problem of multilingualism in the Information Society. Bulletin of the Kemerovo State University of Culture and Arts, (15), 8-17. https://www.elibrary.ru/item.asp?id=16562224

Kolin, K. K. (2012). Philosophical Problems in Informatics Science [信息 科學 中 的 哲學 問題]. China Social Sciences Press. https://www.elibrary.ru/item.asp?id=32706200

Kolin, K. K. (2014). The Systemic Crisis of culture: The structure and content of the problem. Strategic Priorities, (3), 6-27. https://www.elibrary.ru/item.asp?id=23604839

Kolin, K. K. (2015). Social Informatics: 25 years of development of the Russian scientific school. Strategic Priorities, (4), 51-63. https://www.elibrary.ru/item.asp?id=25790517

Kolin, K. K. (2016). Outstanding Scientist of Our Time: to the 80th Anniversary of Academician A.D. Ursul. Journal of Siberian Federal University - Humanities and Social Sciences, 9(9), 2194-2201. https://doi.org/10.17516/1997-1370-2016-9-92194-2201

Kolin, K. K. (2017). The Technological Society: Global Trends, Challenges, and Threats. Strategic Priorities, (1), 4-15. https://www.elibrary.ru/item.asp?id=29432620

Kolin, K. K. (2018). Quality of Life: a new measurement methodology. Strategic priorities, (4), 77-93. https://www.elibrary.ru/item.asp?id=37621795

Kolin, K. K. (2020a). Modern Problems of Global Security. Strategic priorities, (3-4), 15-29. https://www.elibrary.ru/item.asp?id=44309791

Kolin, K. K. (2020b). Information Security: a new content of a complex problem. Strategic priorities, (3-4), 55-62. https://www.elibrary.ru/item.asp?id=44541660

Kolin, K. K., Sokolova, I. V., \& Suslakov, B. A. (1997). Experience of studying the problems of social informatics in the Russian education system. In Proceedings of the II International Congress of UNESCO "Education and Informatics". IITE.

Kolin, K. K., \& Ursul, A.D. (2011). Information Culturology: The subject and tasks of a new scientific direction. LAP. https://www.elibrary.ru/item.asp?id=25880049

Kolin, K. K., \& Ursul, A. D. (2015). Information and Culture. Introduction to Information Culturology. Strategic priorities. https://www.elibrary.ru/item.asp?id=24174063

Kolin, K. K., \& Khoroshilov, A. A. (2012). The problem of Multilingualism in the Information Society and new intellectual translation technologies. Information Society, (2), 62-67. https://www.elibrary.ru/item.asp?id=18051456

MOFA. (2000). Okinawa Charter on Global Information Societ. Ministry of Foreign Affairs of Japan. https://www.mofa.go.jp/policy/economy/summit/2000/documents/charter.html

RIC. (2021). Колин Константин Константинович. The Russian Intellectual Club. http://www.rikmosgu.ru/about/members/Kolin/

Sokolov, A.V. (1988). Information approach to documentary information. Leningrad State Institute of Culture. https://search.rsl.ru/ru/record/01001466026 
Sokolov, I. A., \& Kolin, K. K. (2009). Development of the Information Society in Russia and actual problems of Information Security. Information Society, (4-5), 98-106. https://www.elibrary.ru/item.asp?id=12835524

UN. (2018). Internet milestone reached, as more than 50 percent go online: UN telecoms agency. https://news.un.org/en/story/2018/12/1027991

UNESCO. (1996). 2nd International Congress on Education and Informatics. http://archive.iite.unesco.org/publications/3214575/

Ursul, A. D. (1990a). Informatization of society. Introduction to Social Informatics. Academy of Social Sciences under the Central Committee of the CPSU. https://search.rsl.ru/ru/record/01001574442

Ursul, A. D. (1990b). Informatization of society and Social Informatics. In Kolin, K. K., Suslakov, B. A. (eds.), Social Informatics (pp. 3-12). Higher Komsomol School under the Central Committee of the Komsomol. https://www.elibrary.ru/item.asp?id=25753672

Editorial record: The article has been peer-reviewed. First submission received on 15 January 2021. Revision received on 7 May 2021. Accepted for publication on 22 May 2021. The editors coordinating the peer-review of this manuscript were Vasja Vehovar (iD, Zdenek Smutny (D), and Alice R. Robbin (D. The editor in charge of approving this manuscript for publication was Zdenek Smutny.

Special Issue: Perspectives of Social Informatics.

Acta Informatica Pragensia is published by Prague University of Economics and Business, Czech Republic.

ISSN: $1805-4951$ 